\title{
Is sedentary behavior an intervening factor in the practice of physical activity in the elderly?
}

Daniel Vicentini de Oliveira ${ }^{1}$

Maria do Carmo Correia de Lima ${ }^{1}$ Gustavo Vinicius do Nascimento de Oliveira²

Sônia Maria Marques Gomes Bertolini³ José Roberto Andrade do Nascimento Júnior ${ }^{4}$ Cláudia Regina Cavaglieri ${ }^{5}$

\section{Abstract}

Objective: the present study aimed to analyze the association between current sedentary behavior and the practice of physical activity among elderly persons in the city of Maringá in the state of Paraná. Method: a cross-sectional study of 970 elderly subjects was carried out, using the International Physical Activity Questionnaire. Results: the modeling of structural equations revealed that the sedentary behavior has a significant effect $(\mathrm{p}<0.05)$ on the activities moderate and vigorous activities, explaining $3 \%$ and $4 \%$ of the variability of these variables. Specifically, it has been found that increased sedentary behavior has a $(\beta=0.13)$ and negative on vigorous activities $(\beta=-0.21)$. Conclusion: the current state of sedentary behavior has a significant effect on moderate and vigorous activities.
Keywords: Sedentary Lifestyle. Motor Activity. Health of the Elderly.

Universidade Estadual de Campinas, Faculdade de Ciências Médicas, Programa de pós-graduação em Gerontologia. Campinas, São Paulo, Brasil.

2 Centro Universitário Metropolitano de Maringá, Programa de graduação em Educação Física. Maringá, Paraná, Brasil.

3 Centro Universitário de Maringá, Programa de pós-graduação em Promoção da saúde. Maringá, Paraná, Brasil.

4 Universidade Federal do Vale do São Francisco, Programa de pós-graduação em Educação Física. Petrolina, Pernambuco, Brasil.

5 Universidade Estadual de Campinas, Faculdade de Ciências Médicas, Programa de pós-graduação em Gerontologia. Campinas, São Paulo, Brasil.

Funding: Coordination for the Improvement of Higher Education Personnel (CAPES), 01P-3372/2017, Internship Scholarship.

Correspondence

Daniel Vicentini de Oliveira

d.vicentini@hotmail.com 


\section{INTRODUCTION}

The epidemiological and demographic transition in Brazil, combined with the process of urbanization and the advance of technology, have resulted in an increase in longevity and changes in the lifestyle adopted by the population ${ }^{1,2}$. An active lifestyle has been modified by the insufficient practice of physical activity and by sedentary behavior, which brings negative consequences for health and quality of life as we grow older ${ }^{1-3}$.

Sedentary behavior and physical activity have different constructs. The first is related to the set of behaviors adopted in a seated or lying position where little energy is spent and which do not increase energy expenditure above resting levels (1.0 - 1.5 metabolic equivalent tasks - METs). Physical activity is defined as any body movement produced as a result of muscle contraction that results in caloric expenditure ${ }^{3-8}$.

Researchers who have analyzed the impact of physical activity during the aging process through longitudinal studies have found that, as we age, levels of physical activity tend to decrease, while the time spent in sedentary activities tends to increase ${ }^{1,2,9-12}$. According to Amorim and Faria ${ }^{13}$ and Chastin et al ${ }^{14}$, factors that can contribute to this inverse relationship include the absence of facilitators and stimulators for the adoption of healthy habits and the presence of environmental barriers.

In view of the considerations presented, the present study sought to analyze the association between current sedentary behavior and the practice of physical activity of elderly persons in the city of Maringá, Paraná, Brazil.

\section{METHOD}

A quantitative, observational and crosssectional study with an epidemiological approach was carried out.

The authors contacted the Department of Sports and Leisure to seek authorization for the collection of data from Gyms for the Third Age (GTA) of the city of Maringá, Paraná. Next, the same public organ provided information about the quantity and locations of GTAs spread around the municipal region (with the exception of the districts). Of the 57 GTAs identified, 23 were excluded from the survey due to the low prevalence of elderly users and/or the environmental and structural instability of the gyms. A total of 970 elderly people, intentionally chosen and selected for convenience, were therefore enrolled in the study. Elderly patients of both genders, who were users of at least one of the GTAs surveyed and retained their capacity for speech and hearing were included, allowing the questionnaires to be applied. Elderly users of walking aids or with neurological and dementia deficits reported by caregivers and/or relatives at the time of data collection were excluded. Also excluded were elderly individuals with possible cognitive deficits, assessed by the Mini Mental State Exam (MMSE) $)^{15}$.

The cut-off points used for exclusion by the MMSE were 17 for illiterate individuals; 22 for elderly persons with an education of between 1 and 4 years; 24 for those with schooling between 5 and 8 years and 26 for those who had 9 years or more of schooling. These cut-off points were based on the criteria of Brucki, Nitrini and Caramelli ${ }^{16}$. Elderly persons classified below the specific cut off point for their level of schooling were excluded.

The physical activity level of the elderly was evaluated using the short version of the International Physical Activity Questionnaire (IPAQ). The level of physical activity was classified as sedentary, irregularly active, active or very active. Sedentary behavior was assessed through the average sitting time on a weekday and on a weekend day ${ }^{17}$.

A team of ten researchers was previously trained and, after a pilot data collection, were distributed among the research sites. The researchers approached the elderly in the GTAs themselves, on different days of the week and at different times. Data collection took place between March and July 2017.

Preliminary analyzes. Preliminary data analysis was performed using the Kolmogorov Smirnov normality test. Spearman's correlation (non-parametric) was used to verify the relationship between the variables. According to the statistical recommendations, the following cut-off points were used for the correlation coefficients: $\mathrm{r}<0.40=$ weak correlation, $\mathrm{r}>0.40$ to $0.69=$ moderate correlation, $r>0.69=$ strong correlation $^{18,19}$. 
The main analysis involved Structural Equation Modeling (SEM). The hypothetical model verified the existence of four latent factors (Sedentary Behavior, Light Activities, Moderate Activities and Vigorous Activities) from the observed variables of the questionnaires used. Similar procedures to generate latent variables from the dimensions of the questionnaires have been adopted by several researchers in the area of health ${ }^{20,21}$. In this way, the assumptions described in the hypothetical model were tested by SEM, verifying how sedentary behavior affects the practice of physical activity among the elderly.

SEM was tested using the two-step method: Step 1) specify and identify the submodel of the measurement by performing confirmatory factor analysis (CFA) of the measurement model; and Step 2) Specify and identify the structural submodel, establishing trajectories and errors for the endogenous variables $^{20}$. The quality of fit of the model was analyzed according to the fit indices and the local fit was evaluated by the factorial loads and the reliability of the items. The maximum likelihood estimation method was used to estimate the parameters of the model. The existence of outliers was checked by means of the square Mahalanobis distance $\left(\mathrm{D}^{2}\right)^{22}$. Univariate distribution was also evaluated through asymmetry (ISkI <3.0) and kurtosis (IKuI <10), and multivariate distribution (Mardia coefficient for multivariate kurtosis) ${ }^{23}$. The indicators of the goodness of fit of the model (Absolute, Incremental and Parsimonious Fit) were: $\mathrm{X}^{2} / \mathrm{gl}$ (values between 1.0 and 3.0 are satisfactory), Root Mean Square Error of Approximation (RMSEA) (less than 0.06), Tucker-Lewis index (TLI) and the Comparative Fit Index (CFI) close to 0.95$)^{24}$. The interpretation of the coefficients of the trajectories had as a reference: little effect for factor loadings $<0.20$, medium effect for factor loadings up to 0.49 and great effect for factor loadings $>0.5021$. The level of significance was set at $\mathrm{p}<0.05$.

This study was approved by the Committee of Ethics in Research with Human Beings (CEP) of the Faculdade Metropolitana de Maringá, under approval number 2,255,102/2017. The elderly who agreed to participate in the study signed a free and informed consent form (FICF).

\section{RESULTS}

A total of 970 elderly men and women (428 men and 542 women) aged between 60 and 91 years $(68.9( \pm 6.9))$ participated in the study. There was a prevalence of married elderly persons (62.1\%), aged $60-69$ years $(60.4 \%)$, who were white $(75.9 \%)$, retired $(72.9 \%)$ and earned from 1 to 2 minimum wages (53.3\%). It was also observed that the majority of the elderly had not finished high school (63.9\%).

Table 1 shows the descriptive values of each of the study variables, as well as the correlation values between the variables. Sedentary behavior presented the following correlations with the practice of physical activity: time sitting during the week with days of walking $(\mathrm{r}=-0.19)$; minutes of walking per week $(r=-0.08)$; days of moderate activity $(r=-$ $0.23)$; minutes of moderate activity per day $(\mathrm{r}=-0.10)$; minutes of moderate activity per week $(\mathrm{r}=-0.14)$; days of vigorous activity $(r=-0.36)$; minutes of vigorous activity per day $(\mathrm{r}=-0.29)$ and minutes of vigorous activity per week $(\mathrm{r}=-0.34)$. 
Table 1. Matrix of correlation between variables of sedentary behavior and practice of physical activity practice.

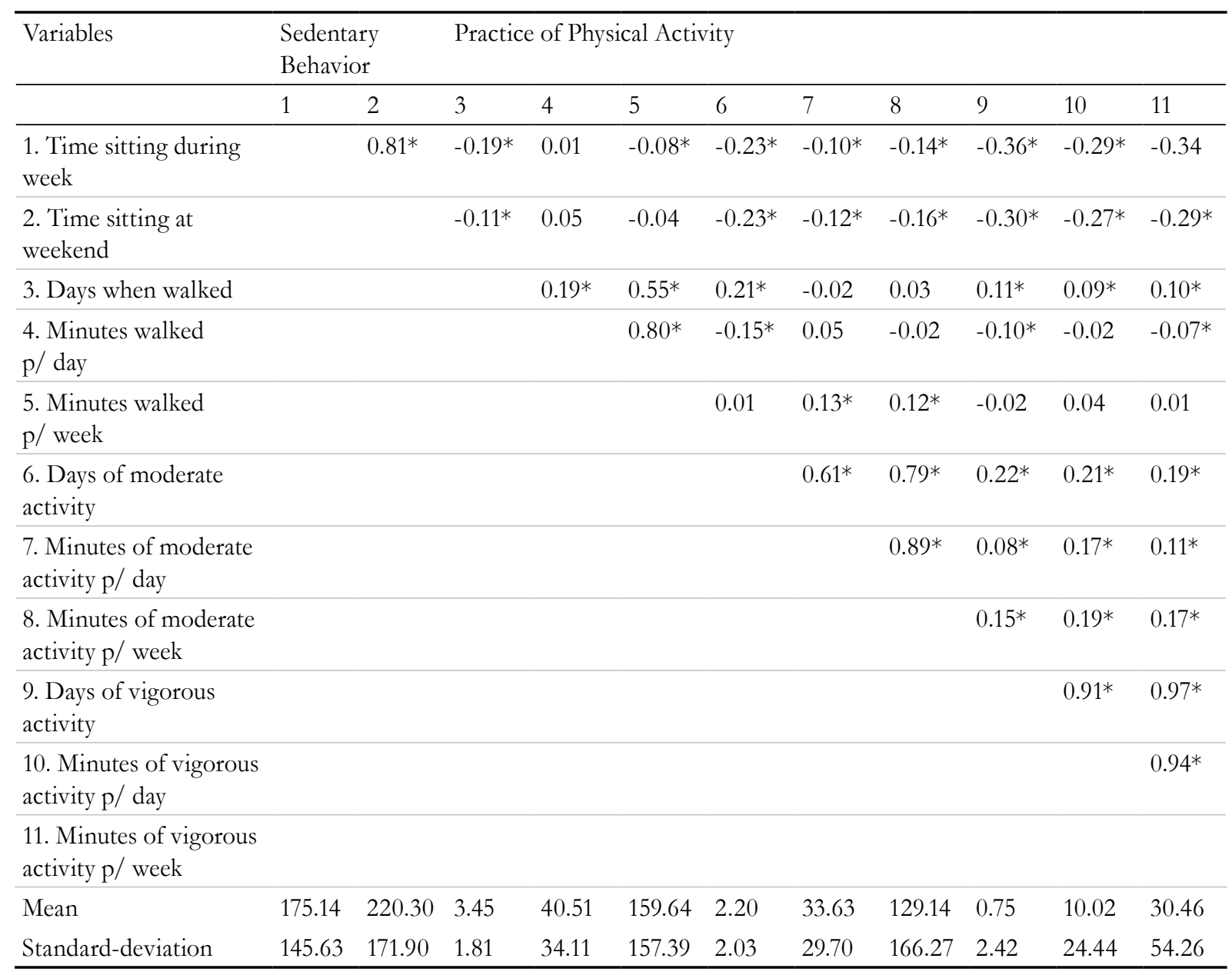

*Significant correlation $-p<0.05$.

\section{Structural Equation Modeling}

The measurement model (Step 1) with the submodels of the four latent variables exhibited acceptable indices $\left[\mathrm{X}^{2}(38)=274.25 ; \mathrm{p}=0.0001 ; \mathrm{X}^{2} / \mathrm{gl}\right.$ $=3.21$; CFI $=0.97$; GFI $=0.95 ;$ TLI $=0.95$; $\mathrm{RMSEA}$ $=0.08 ; p($ RMSEA $<0.05)=0.001]$. The quality of the local fit and the internal reliability of the items was also confirmed, with all trajectories obtaining significant factorial loadings $(p<0.05)$ and $>0.50$. The hypothetical model was then analyzed (Step 2), verifying whether current sedentary behavior would affect the practice of light, moderate and vigorous physical activities among the elderly.

The model (M1) tested (Figure 1) presented sufficiently acceptable indicators of fit $\left[\mathrm{X}^{2}(41)=\right.$ 283.71; $p=0.001 ; \mathrm{X}^{2} / \mathrm{gl}=5.920 ; \mathrm{CFI}=0.97$; GFI $=$ $0.95 ; \mathrm{TLI}=0.96 ; \mathrm{RMSEA}=0.08 ; \mathrm{p}(\mathrm{RMSEA}<0.05)$ $=0.001 ; \mathrm{AIC}=333.71 ; \mathrm{BIC}=544.64 ; \mathrm{MECVI}=$
0.35]. However, the regression coefficient $(\beta=-0.03)$ of Sedentary Behavior for Light Activities did not present a significant effect $(\mathrm{p}=0.065)$. The Light Activities variable was therefore excluded, and the model tested again.

The modified model (M2) presented significant trajectories $(p<0.05)$ and satisfactory indicators of fit $\left[\mathrm{X}^{2}(17)=72.37 ; \mathrm{p}=0.001 ; \mathrm{X}^{2} / \mathrm{gl}=3.26\right.$; CFI $=0.99 ; \mathrm{GFI}=0.98 ; \mathrm{TLI}=0.98 ; \mathrm{RMSEA}=0.06$; $\mathrm{p}(\mathrm{RMSEA}<0.05)=0.561 ; \mathrm{AIC}=110.37$; $\mathrm{BIC}=$ 203.04; MECVI = 0.11] (Table 2).

The latent variables of Moderate Activities and Vigorous Activities were explained by $3 \%$ and $4 \%$, respectively, by Sedentary Behavior in M2 (Figure 2). In the direct relationship established between Sedentary Behavior and Moderate Activities and Vigorous Activities, the effects were weak $(\beta=0.13$ and $\beta=-0.21)$, indicating that with each increase of 
one standard deviation in the Sedentary Behavior unit there was an increase of 0.13 standard deviation in the Moderate Activities unit and a reduction of 0.21 standard deviation in the Vigorous Activities unit.
In addition, the Bias-corrected confidence interval analysis generated by bootstrap replication revealed a significant effect of Sedentary Behavior on Moderate Activities and Vigorous Activities.

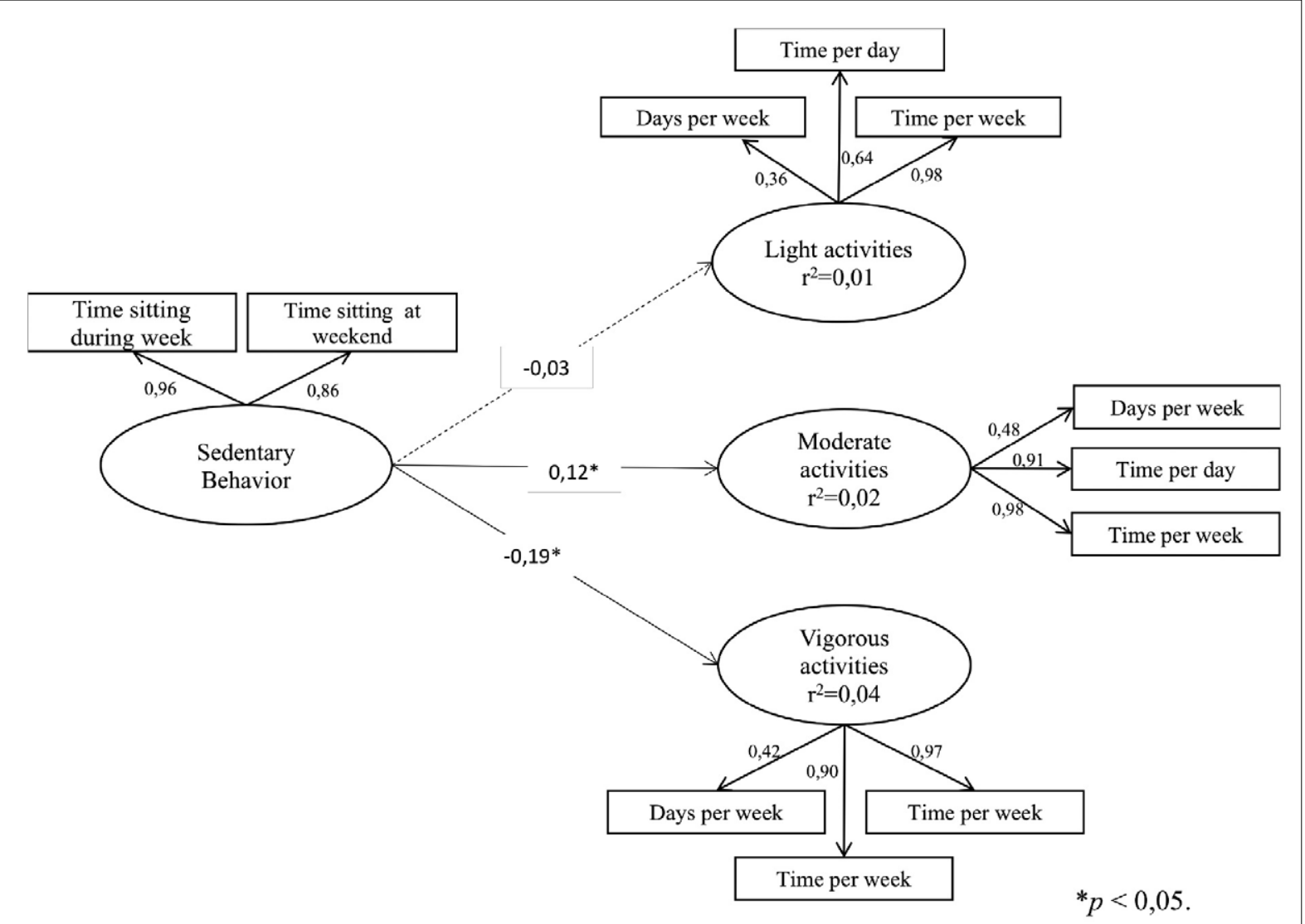

Figure 1. Structural model (M1) of the effect of sedentary behavior on the physical activity of the elderly.

Table 2. Comparison of indices of fit of the models proposed by the study.

\begin{tabular}{lll}
\hline Comparison between models & Model 1 & Model $2^{*}$ \\
\hline Chi-squared & 283,71 & 72,37 \\
Degrees of freedom & 41 & 17 \\
$p$-value & 0,001 & 0,001 \\
$X^{2}$ standardized $\left(X^{2} / \mathrm{gl}^{* *}\right)$ & 5,92 & 3,26 \\
Adjusted Goodness of Fit Index & 0,95 & 0,98 \\
Root Mean Square Error of Approximation $\left[\mathrm{CI}^{* * *} 90^{\circ}\right]$ & $0,08[0,07-0,09]$ & $0,06[0,04-0,07]$ \\
Tucker-Lewis index & 0,96 & 0,98 \\
Comparative Fit Index & 0,97 & 0,99 \\
Akaike Information criteria & 333,71 & 110,37 \\
Bayes Information criteria & 5444,64 & 203,04 \\
Expected Cross Validation Index & 0,35 & 0,11 \\
\hline
\end{tabular}

${ }^{*}$ Model with best fit adopted; $* *$ Chi-square ratio by degrees of freedom; ${ }^{* *} \mathrm{CI}=$ Confidence Interval. 


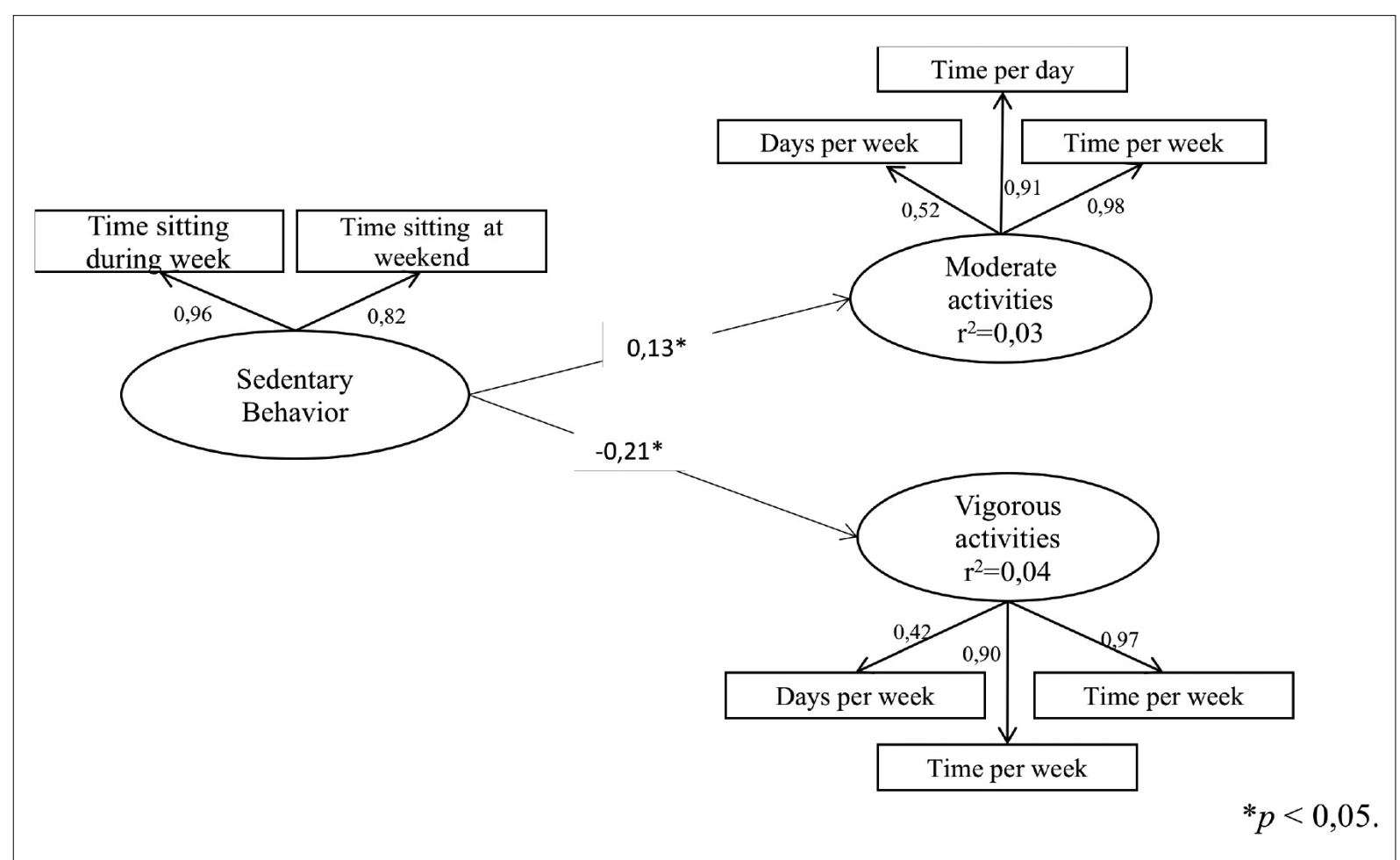

Figure 2. Structural model (M2) of the effect of sedentary behavior on the physical activity of the elderly.

Although the effects of the model are considered weak, the findings show that sedentary behavior negatively affects vigorous activities in the elderly and positively affects the performance of moderate activities.

\section{DISCUSSION}

The present study analyzed the effect of sedentary behavior on the practice of physical activity among elderly users of GTAs, finding that as the sedentary behavior of the elderly increases, the practice of vigorous physical activities decreases and that of moderate activities increases. In this sense, the present result sums up the evidence of factors that can interfere in the practice of physical activity by revealing the significant effect of sedentary behavior on moderate and vigorous activities ${ }^{4,5,25}$. It was observed that in general, sedentary behavior negatively affects the performance of vigorous activities in the elderly and positively affects the performance of moderate activities.
Many studies have already proven the importance of physical activity in promoting a more active and healthy lifestyle and also shown that sedentary behavior can negatively affect the health, functional capacity and quality of life of the elderly, who represent the most sedentary segment of society ${ }^{3,4,5,7,16,25,26}$.

In the interests of active and healthy aging, the World Health Organization (WHO) advocates that elderly persons who are 65 years of age or older practice at least 150 minutes per week of moderate intensity activities or at least 75 minutes per week of vigorous intensity activities, or an equivalent combination of moderate and vigorous activities, in addition to their daily routine activities, in order to optimize cardiorespiratory fitness, muscle and bone condition and reduce the risks of chronic non-communicable diseases, depression and cognitive decline. When unable to follow these recommendations due to health and functional impairment, the elderly should be physically active to the extent their ability allows ${ }^{27}$. 
Some limitations of the present study should be highlighted. First is the fact that it is a cross-sectional study, which makes it difficult to assess the temporal relationship between sedentary behavior and the variables of interest, and so cause and effect cannot be established ${ }^{28}$. The investigation was performed only among elderly users of GTAs and in a single Brazilian municipal region, which does not reflect the reality and profile of the elderly in general. Finally, with regard to the specific questions used to assess sedentary behavior, there remains a lack of common use tools, which makes it difficult to compare the basis of the present discussion due to the fact that several forms of evaluation exist, including selfreporting, accelerometer use, IPAQ, and human activity profiling, among others ${ }^{29}$.

For future investigations, studies with greater power for analyzing cause and effect analysis, preferably longitudinal in design, are suggested. The

\section{REFERENCES}

1. de Rezende LFM, Rey-López JP, Matsudo VKR, Luiz OC. Sedentary behavior and health outcomes among older adults: a systematic review. BMC Public Health. 2014;14:1-9.

2. Meneguci J, Santos DAT, Silva RB, Santos RG, Sasaki JE, Tribess S, et al. Comportamento sedentário: conceito, implicações fisiológicas e os procedimentos de avaliação. Motricidade. 2015;11(1):160-74.

3. LukaK A, Heier M, Thorand B, Laxy M, Nowak D, Peters A, et al. Physical activity levels, duration pattern and adherence to $\mathrm{WHO}$ recommendations in German adults. Plos One. 2017;12(2):1-9.

4. Owen N, Healy GN, Matthews CE, Dunstan DW. Too much sitting: the population health science of sedentary behavior. Exerc Sport Sci Rev. 2010;38(3):105-13.

5. Leask CF, Harvey JA, Skelton DA, Chastin SF. Exploring the context of sedentary behaviour in older adults (what, where, why, when and with whom). Eur Rev Aging Phys Act. 2015;12:1-16.

6. van Holle V, van Cauwenberg J, de Bourdeanudhuij I, van de Weghe $\mathrm{N}$, van Dyck D. Interactions between Neighborhood Social environment and walkability to explain Belgian older adult's physical activity and sedentary time. Int J Envirom Res Public Health. 2016;13(6):1-53. inclusion of other quantitative and more operational variables, such as the use of an accelerometer and the human activity profile, which provide more detailed information about the profile of the elderly and the presence of barriers and facilitators of the practice of physical activity, is recommended.

\section{CONCLUSION}

It can be concluded that the state of sedentary behavior negatively affects the performance of vigorous activities among the elderly and positively affects the performance of moderate activities.

Such a finding may provide indicators to support new forms of working and the development of strategies of adherence to these activities among the elderly to reduce the negative consequences of sedentary behavior and thus promote a more active and healthier lifestyle.

7. Scholes S, Bridges S, Fat LN, Mendell J. Comparison of the physical activity and sedentary behavior assessment questionnaire and the short-form international physical activity questionnaire: an analysis of health survey for England data. Plos ONE. 2016;11(3):1-30.

8. Burton NW, Haynes M, van Uffelen JGZ, Brown WJ, Turrell G. Mid-aged adults' sitting time in three contexts. Am J Prev Med. 2012;42(4):363-73.

9. Evenson KR, Morland KB, Wen F, Scanlin K. Physical activity and sedentary behavior among adults 60 years and older: New York City Residents compared to a National Sample . J Aging Phys Act. 2014;22(4):499-507.

10. Stamatakis E, Davis M, Stathi A, Hamer M. Associations between multiple indicators of objectively-measured and self-reported sedentary behaviour and cardiometabolic risk in older adults. Prev Med. 2012;54(1):82-7.

11. Sugiyama T, Merom D, Van der Ploeg HP, Corpuz G, Bauman A, Owen N. Prolonged sitting in cars: prevalence, socio-demographic variations, and trends. Preventive Medicine. 2012;55(4):315-8.

12. Meneguci J, Garcia CA, Sasaki JE, Virtuoso Júnior JS. Atividade física e comportamento sedentário: fatores comportamentais associados à saúde de idosos. Arq Ciênc Esporte. 2016;4(1):27-8. 
13. Amorim PRS, Faria FR. Dispêndio energético das atividades humanas e sua repercussão para a saúde. Motricidade. 2012;8(Supl. 2):295-302.

14. Chastin SF, Fitzpatrick N, Andrews M, DiCroce N. Determinants of sedentary behavior, motivation, barriers and strategies to reduce sitting time in older women: a qualitative investigation. Int J Environ Res Public Health. 2014;11:773-91.

15. Folstein MF, Folstein SE, McHugh PR. Mini Mental state: a practical method for grading the cognitive state of patients for the clinician. J Psychiatr Res. 1975;12(3):189-98.

16. Brucki SMD, Nitrini R, Caramelli P, Bertolucci PHF, Okamoto IH. Sugestões para o uso do miniexame do estado mental no Brasil. Arq Neuropsiquiatr. 2003;61(3B):770-81.

17. Matsudo S, Araújo T, Matsudo V, Andrade D, Andrade E, Oliveira LC, et al. Questionário Internacional de Atividade Física (Ipaq): Estupo de Validade e reprodutibilidade no Brasil. Rev Bras Ativ Fís Saúde. 2001;6(2):5-14.

18. Nunnally JC, Berstein IH. Psychometric theory. New York: McGraw-Hill; 1994.

19. Hair J, Black W, Babin B, Anderson R, Tatham R. Multivariate data analysis. Hoboken: Pearson Education; 2014.

20. Campana AN, Tavares MC, Silva D. Modelagem de Equações Estruturais: Apresentação de uma abordagem estatística multivariada para pesquisas em Educação Física. Motricidade. 2009;5(4):59-80.
21. Fernandes H, Vasconcelos-Raposo J, Lázaro JP, Dosil J. Validación e aplicación de modelos teóricos motivacionales en el contexto de la educación física. Cuad Psicol Deporte. 2004;4:67-89.

22. Marôco J. Análise de equações estruturais: Fundamentos teóricos, software \& aplicações. ReportNumber; 2010.

23. Kline RB. Principles and Practice of Structural Equation Modeling. New York: Guilford Press; 2012.

24. Hu L, Bentler P. Cutoff criteria for fit indices in covariance structure analysis: conventional criteria versus new alternatives. Struct Equat Model. 1999;6:1-55.

25. Santos RG, Medeiros JC, Schimitt BD, Meneguci J, Santos DAT, Damião R, et al. Comportamento Sedentário em Idosos: uma revisão sistemática. Motricidade. 2015;11(3):171-86.

26. Von Bonsdorff M, Rantanen T. Progression of functional limitations in relation to physical activity: a life course approach. Eur Rev Aging Phys Act. 2011;8(1):23-30.

27. World Health Organization. Global recommendations on physical activity for health. [Internet]. Geneva: World Health Organization; 2010 [acesso em 03 2016]. Disponível em: http://apps.who.int/iris/ bitstream/10665/44399/1/9789241599979_eng.pdf

28. Pereira MG. Epidemiologia: teoria e prática. Rio de Janeiro: Guanabara Koogan; 1995.

29. Suzuki CS, Moraes AS, Freitas ICM. Média diária de tempo sentado e fatores associados em adultos residentes no município de Ribeirão Preto SP, 2006: projeto OBEDIARP. Rev Bras Epidemiol. 2010;13(4):699-712. 